\title{
Technological, Economic and Social Aspects of Management by Development of the Digital Industry 4.0
}

\author{
Evgeniy Bryndin \\ Research Centre "NATURAL INFORMATIC", National Supercomputer Technological Platform, Novosibirsk, \\ Russia
}

*Corresponding Author: Evgeniy Bryndin, Research Centre "NATURAL INFORMATIC", National Supercomputer Technological Platform, Novosibirsk, Russia

\begin{abstract}
The industry 4.0 is means of increase in efficiency of workers. During an era of digital economy of technology turn into workers, strongly washing away border between opportunities of work and the capital. A driving factor of all processes is expansion of computer technologies. Approaches to business under the influence of development of technologies changed, the need for hiring of employees for realization of daily routine tasks which was always the most important part of activity of any company in particular sharply decreased. Algorithms and technologies which do routine work, or its considerable proportion are developed. There is more and more deep penetration into our life of such phenomenon as "larger data". The organizations collect unimaginable amount of information practically about all aspects of the activity, these data include detailed data on a huge set of an art and operations. Computers learn to master easily and quickly new skills, especially when they have an access to the large volume of data for tutoring. The digital industry changes sectors of economy and labor market. There is an interaction of technologies and economy. New social policy and infrastructure of digital economy, financial system, labor market and education is built.
\end{abstract}

Keywords: digital industry, neuronic network, larger data, infrastructure of digital economy, social policy.

\section{INTRODUCTION}

Informational technologies become the really universal, and their influence is felt strongly in all spheres [1]. The probability that in process of introduction of new technologies in business - models practically in all existing branches decrease in need for work of the person will be observed is high. At the same time it is possible not to doubt that in new branches which will appear in the future since the moment of their birth all last achievements from the world of technologies for the purpose of economy of expenses on personnel will be actively used. For example, such companies as Google and Facebook, became a part of the life of all and everyone and achieved space body height of capitalization, using work absolutely small — concerning their size and influence - number of people. There are all bases to believe that the overwhelming majority of new branches will be created and develop in the future according to the similar scenario. New technologies are capable to undermine existence of the whole branches or to change the particular sector of economy and labor market to unrecognizability.

All this indicates that we enter a digital era of changes which will be followed by the enormous pressure upon economy and society. In the next years and decades interaction of technologies and economy is necessary to almost all areas of human activity. A feed-back between labor productivity, body height of salaries and increase in consumer expenses which so efficiently worked still will be broken. We will face a problem of lack of number of solvent consumers which is necessary for natural body height, focused on the mass market, economy.

Economic recovery without creation of jobs becomes norm. The financial sector does not create actual cost and does not promote body height of the common welfare of society; he only looks for more and more sophisticated ways of pumping out of profits and wealth from other sectors of economy. Economists found steady correlation between body height of the financial sector and inequality and also reduction of a share of work in national income. The financial sector gets profit on actual economy, and then redistributes it in favor of those who are at top of hierarchy of distribution of income. Body height in the financial sector to a large extent depends on information technology 
development. Two thirds of trade operations on securities markets are carried out in the automatic mode on speculative algorithms now.

It is necessary to reconstruct infrastructure of digital economy, a financial system, labor market, education and social policy to keep the worthy level of the material well-being

\section{Robotization Of The Production And Social SPHERE}

Certainly, in use of robots in the industrial production there is nothing new. They are more narrow than steel irreplaceable practically in all industries - from automotive industry before production of semiconductors. At the plant of the producer of electric vehicles Tesla in Fremonte, in the State of California 160 universal production robots assemble about 400 cars a week. As soon as the chassis of the new car appears in the following point of the assembly line, to it several manipulators fall at once and begin to work in close interaction with each other. Robots are capable to change self-contained the tools established on manipulators that allows to carry out various tasks. For example, the same robot at first mounts seats, and then, having changed tools, causes the gluing structure and establishes a windshield. According to the International federation of robotics, during the period from 2000 to 2012 the world sales volume of the production robots grew more than by $60 \%$, having reached $\$ 28$ billion in 2012. The absolute leader in growth rates is the market of China where during the period from 2005 to 2012 the annual rate of an increase of number of the installed robots was about $25 \%$.

The combination of technologies of a vision, space calculations and developed means of manipulation of objects is the cornerstone of development of the Industrial Perception company. It is possible to tell that its emergence means overcoming the last boundary on the way to the full automation behind which robots begin to apply already and for not numerous types of manual skills which are for the present carried out by people. Now there is a problem of creation of the universal robots capable to adapt to conditions of short life cycle of production. Considering ability of the universal robots to work without breaks and fast training in new types of works, their appeal alternatively to the person grows [2-5].

Characteristic strategy of automation was developed and realized by the Japanese network of sushi Kura restaurants. At 262 restaurants of network robots help to cook sushi, and the place of waiters was taken by conveyer belts. That sushi were fresh, the express system watches duration of finding of plates on a tape and automatically moves away them after particular time. Having come to restaurant, clients do the order by means of touch panels, and after a meal put empty plates in an express opening near a table. The system automatically forms the account, washes the dishes and returns it on kitchen. Instead of appointment in each restaurant of the certain head the Kura company created uniform control center from which it is possible to control in the remote mode practically all aspects of work of restaurants. Thanks to transition to business - the model based on automation, Kura was succeeded to reduce the cost of a plate of sushi to $¥ 100$ (about \$1) that gives it huge advantage before competitors.

Many of working methods which were efficient for Kura - in particular automation of process of cooking and the centralized management - finally will be widely adopted in the industry of fast food. Many already take steps in this direction (Figure 1).
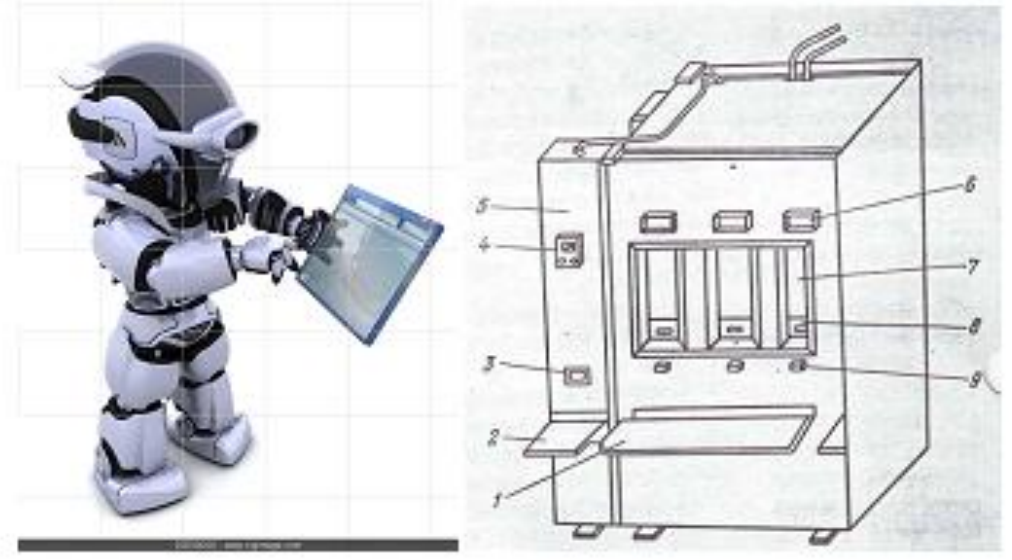

Figure 1 
When one of the main players in branch begins to take advantages of automation, others remain nothing else how to follow his example. And automation is not only decrease in expenses on personnel, but also some other competitive advantages. For example, participation of robots in preparation can be considered as a way of ensuring compliance to sanitary and hygienic requirements as less people come into contact with food. At the same time not only the speed and accuracy of implementation of the order, but also level of inquiries during the work with certain clients increase: as soon as special preferences of the client become known at one restaurant, information on them will get also to other institutions of network, providing equally high level of satisfaction of inquiries of clients in each of them.

Rapid growth of the sector of self-service, i.e. intelligent vending machines and booths becomes a factor of future automation. Scope of vending machines is not limited to sale of sparkling water, chocolate bars and terrible instant coffee for a long time: at many airports and expensive hotels the composite automatic machines selling a consumer electronics engineering are installed including iPod, iPad and other devices of the Apple company now. AVT Inc company. taking the leading positions in production of vending machines, says that it can design to order the system of self-service practically for any goods. Use of vending machines allows to reduce considerably three main types of expenses in the sphere of retail trade: rent, work and theft of goods by clients and employees. Besides an around the clock duty, many automatic machines are equipped with video screens for demonstration of the target advertizing designed to draw an attention of clients to products, the bound to the sold goods. In other words, they are capable to replace the seller even in it. Also they give to clients an opportunity to enter the e-mail address and to receive on it the check. Thus, in essence, automatic machines have many of advantages of the order of goods on the Internet behind one important exception - the client can receive item at once.

The Internet - shops led market capture to movement of employees from habitual shops on warehouses and in the centers of a logistics. Functions of the employee of a warehouse give in to automation much easier, than duties of the employee of shop.

When the trading companies are engaged in full modernization of the outlets, turning them into huge vending machines. Such shop will consist of the automated warehouse with the trading floor adjoining it in which clients will be able to get acquainted with product samples and to make the order. After obtaining the order goods will be immediately transferred to buyers or even to be delivered by means of robots to their cars.

With perfecting and increase in availability of technologies of voice-activated control on which, for example, work of Siri voice assistant of the Apple company is based already very soon buyers will ask for the help the mobile devices in the same way as they do it at communication with the employee of shop. The single difference, certainly, that the client should not wait when the employee is released or to look for it; the virtual assistant will be always available, and his answers practically will always be the exact.

"Cloudy robotics" can appear one of the main propellents of future revolution in the world of robotics. It is a number of technologies for transfer of a big share of the computing tasks providing control of mobile robots in the potent centralized computing clusters. Cloudy robotics became possible thanks to enormous jump in transfer rate of data; now there is an opportunity to unload characteristic systems of the composite robotics, having transferred the considerable proportion of calculations to huge dataprocessing centers and along with it having provided to robots access to network resources. Thus, there is an opportunity to create cheaper robots as now for work they need less computing power and memories. One more advantage - a possibility of expeditious updating of the software by several cars is simultaneous. When one robot uses the centralized computing resources for tutoring and adaptation by Wednesday, this again acquired knowledge can be instantly imparted to other cars at their appeal to system that simplifies process of scaling of results of machine learning during the work with a large number of robots. For example, the Google company which provides support of technologies of cloudy robotics provides the interface giving to robots the chance to take all advantage of Google services to devices under control of the Android operating system.

Cloudy robotics can exert the most noticeable impact in areas which assume access to huge databases and also potent computing resources [6-7]. For example, as a discernment of visions the robot which 
could perform various works, the bound to housekeeping. To be tidied up in the room, the robotic housemaid has to be able to distinguish a set of objects and know what with them to do.

In process of overcoming by technologies all of new boundaries many jobs which we consider far from a routine today and therefore protected from automation threat, finally will appear in category sample and easily programmable. The tendency to narrowing of average segments of already polarized labor market, most likely, will proceed, being followed by further approach of robots and technologies of self-service to low-paid jobs and body height of threat for the professions demanding high qualification, from outside more and more "clever" algorithms. If the intellectual software is capable as it is approved by experts of Narrative Science, to compete with the most talented analysts, body height of need for experts whose work is bound to brainwork, in the future it appears under a larger question.

Technologies will lead to fundamental reorganization of labor market and finally will force to revise completely the principles of work of our economic system and a condition of the public contract.

\section{TeChNologies With LARger Data}

The ability to continuously process a flow of unstructured information from a set of various sources in the external environment always fell into to number of adaptation mechanisms, unique for the person. A difference, certainly, that the person will never be able to operate with the large volume of data in the same scales, as computers. Larger data make revolutionary impact on a wide range of areas, including business, policy, medicine and practically all spheres of activity [8-9].

Thanks to larger data the largest retailers can gain rather detailed impression about consumer preferences of certain consumers that gives them the chance to formulate address offers and by that to increase characteristic revenue, at the same time increasing loyalty of clients. Larger data can become for management a source of the most detailed data on the most wide range of questions: all - from parameters of operation of each separate machine to the common results of work of the international corporation - can be potentially subjected to the analysis with such degree of a detail which was simply impossible before.

The machine learning - a method at which the computer touches data and, in fact, writes characteristic program on the basis of the found statistical regularities - is one of the most effective remedies of extraction of the most valuable information. Process of machine learning breaks into two stages: at first the algorithm studies at the available data, and then is applied to new information to the solution of similar tasks. Tutoring is considered ended when the state at which the frequency of the correct answers ceases to grow is reached.

As soon as technologies of neuronic networks with a possibility of profound tutoring and the systems of generation of a coherent written language appear on cloud platforms, they will turn into structural blocks which can be combined a set of different ways. It is necessary to wait for day when there is an architecture of a neuronet and an algorithm of its tutoring which, having gone deep into digital traces of larger data, will teach it to any profession.

Developers of the Deep Mind company, by means of the training system created on the basis of the Quake III shooter and the arcadian games Atari, developed a new algorithm of machine learning IMPALA which allows separate parts of system to study realization of several tasks at once, and then to exchange knowledge among themselves. In many cases of collected data it can appear enough for automation of specific objectives and even the whole types of professional activity.

Just as the person can learn a new profession, having studied experience of predecessors and having tested it in practice at the solution of specific objectives, the modern composite algorithms and technologies, in fact, are capable to do the same and to completely replace the person. Process of automation of professions, the bound to brainwork will look as follows: the team of consultants in the field of informational technologies will come to the large organization and will create there from scratch the systems revolutionary for approaches to business, at the same time doing unnecessary work of hundreds and even thousands of qualified employees.

\section{Technological Creative Thinking And Communication}

Now algorithms and programs which are beyond habitual are developed, getting into spheres which, on belief of an overwhelming majority of experts, are an exclusive prerogative of human consciousness: technologies begin to show signs of creative thinking and communication. 
In 2009. The course Lipson heading Laboratory of creative cars at Cornell University, and the graduate student Michael Schmidt constructed system which was capable to open fundamental laws of the nature self-contained. Lipson and Schmidt began with installation of the double pendulum - the smart mechanism consisting of two pendulums attached to each other. When both pendulums fluctuate, they move on the very composite trajectories which seem chaotic. Further experimenters used sensors and cameras for fixing of driving of pendulums, having received as a result a data flow. At last, they gave to the software an opportunity to self-contained set an initial position of the pendulum. In other words, developers created the researcher with an artificial intelligence who can make characteristic experiments.

They gave to the program the complete freedom: it could release self-contained the pendulum, and then carefully study the obtained data on its movements for the purpose of calculation of the mathematical equations describing behavior of the pendulum. The algorithm controlled all aspects of an experiment; at each repetition he in a random way chose situation from which the pendulum had to begin driving, and then made the analysis and chose new situation which with the greatest probability had to bring closer it to a comprehension of the laws defining driving of the pendulum. Lipson notes that the system "is not a passive algorithm which acts as the ordinary observer. It asks questions. Several clocks were enough for the program which received the name "Eureka" later to formulate a number of the physical laws describing driving of the pendulum including the second Newton's laws; at the same time she could make it, without having obtained beforehand any information on physics or laws of motion and without being programmed on their studying.

In "Eureka" genetic programming - the method repeating the principles of biological evolution is applied. The algorithm begins with drawing up the equations by casual comparison of various structural blocks consisting of mathematical expressions and then checks, how well turned out equations correspond to data [1]. The equations which do not undergo testing are rejected, and those which show a particular potential are rearranged so that finally from them the precise mathematical model could turn out. Process of finding of the equation describing behavior of natural system is creative.

When Schmidt and Lipson published article with the description of the algorithm, the squall of requests for gaining access to their program from other scientists fell upon them. In this regard at the end of 2009 they decided to make "Eureka" available on the Internet. By means of this program it was succeeded to receive interesting results in for time which passed since that moment a number of fields of science, including the simplified option of the equation describing the biochemical nature of bacteria which scientists still cannot understand up to the end. In 2011 Schmidt based a startup of Nutonian, Inc near Boston. for the purpose of commercialization of "Eureka" as the tool of the analysis of larger data as in business, so in the scientific sphere. Transfer of "Eureka" — by an example of the Watson system of the IBM company - on cloudy Wednesday and its transformation into the application which is available to other software developers in the form of the built-in module became one of results of the done work.

Specialists of the Hong Kong firm Hanson Robotics founded in 2003 by David Hanson develop androids with technological thinking and communication, such as BINA48 (Figure 2) and Sophia (Figure 3) [5].

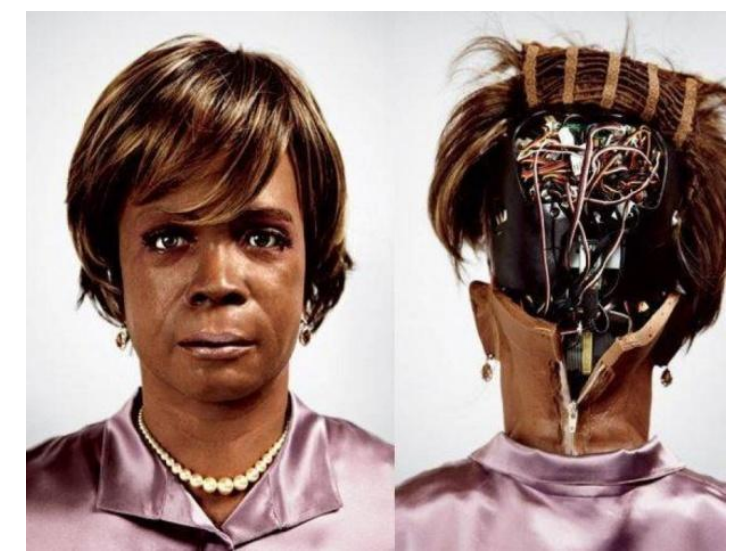

Figure 2 
BINA48 was developed by the Hanson Robots company in 2010. It - the humanoid robot, the copy of the woman by the name of Bina Aspen. Loaded into memory of the android memoirs, feelings, political views of actual Bina. BINA48 can participate in a conversation and show an emotional response, joke and even to philosophize. BINA48 conducts conversations on different intellectual subjects, using actual Bina's manners. BINA48 also has learning capability. Its lexicon and knowledge continue to grow every day of communication with people. For the first time BINA48 (Breakthrough Intelligence via Neural Architecture) finished training at a course love philosophy at the university of Notr-Dam-de-Namur. As writes CNBC, professor of philosophy and the director of laboratory of immersive tutoring and researches of the mixed reality William Barry estimated progress of the robot as "remarkable".

The brain of the android of Sophia is an electronic neuronet. It constantly studies. The android of Sophia can communicate in English and Russian and to ask questions, even to express various emotions - to be surprised, rejoice, long also other. By network use of the SingularityNET platform to create intellectual base for algorithms of an artificial intelligence and to provide a basis for emergence of the first Universal World Artificial Intelligence in Sophia.

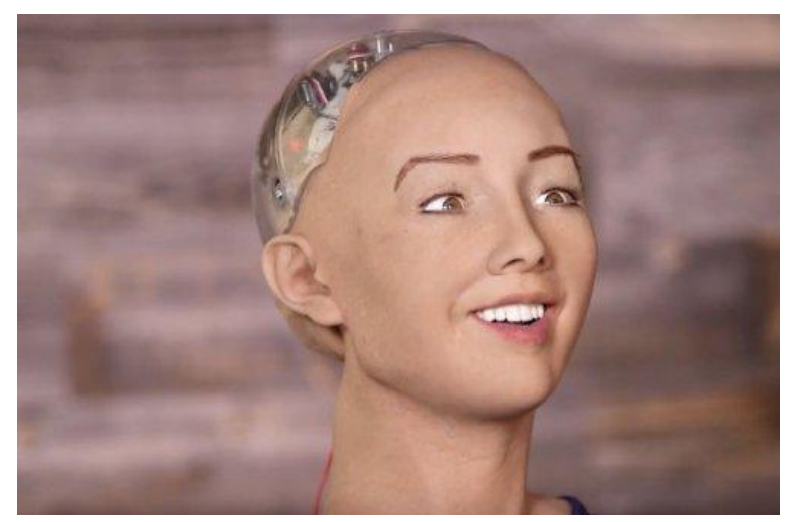

Figure 3

\section{TeChNOLOGiCAL RETRAining}

The mankind lives during an era of fast technological changes. The able-bodied person has to carry out periodically informational control of a brain and sensual control of mentality. Still the retraining problem as a result of development of technologies of automation is, as a rule, solved by granting to workers opportunities for passing of padding tutoring and obtaining new competences. It is considered that so they can pass into other, higher segment of labor market. The fissile introduction of robots and technologies approaches the professions demanding high qualification. In the future all work will be performed in interaction with cars. Training in work with the latest technologies always was a key to successful career [10]. Training during an era of rapid development of technologies demands fast updating of knowledge, available to society. Creation of new online courses and increase in rates of scientific publications will promote technological retraining.

MOOK is the beginning of world revolution in the highest online education. Online courses are capable to connect billions of minds to the solution of global larger problems if to pay the main attention to the highly specialized courses helping those who already work, to receive concrete skills of technical character. For example, such companies as Google and Salesforce, use this educational platform for carrying out the courses designed to teach developers of program tutoring to work with products of these companies.

MOOK continue to develop and be improved, so, the hope that they will make a world revolution which will provide access to high-quality education to hundreds of millions of poor people worldwide, eventually, can be provided. However it is already apparent that in the nearest future the majority of audience of online courses will be made after all by those who already have high motivation for receiving additional education. In other words, MOOK is fated to compete for the same people who go to the routine universities. Assuming that potential employers can consider MOOK as advantage, finally it can lead to radical reorganization of the higher education.

The idea of education on the basis of competence (Competence-Based Education, CBE) was realized in practice by teachers of the Western governor's university (Wester Governer's University. In 
September, 2013. The university of Wisconsin declared introduction of the program on the basis of the analysis of competence with issue of diplomas, it was an incitement to further development of this approach. CBE can be ideal for MOOK as in it the line between courses and the documents on education issued after them is drawn. It opens before the venture capital of an opportunity for creation of firm which will undertake work on carrying out tests and issue of educational documents, without taking any part in troublesome and expensive business of the organization of courses. Students with the sufficient level of motivation will be able self-contained to choose as to them to reach the necessary level of competence, including MOOK, self-education and traditional occupations, and then to pass the test under monitoring of made mention firm for receiving the credits. Such tests can be rather composite, in fact, acting as some kind of filter which partly reminds process of receipt in prestigious educational institutions. Approach will be able to establish strong relations with the largest employers, having provided demand of the graduates in labor market, it will have every chance to turn the industry of the higher education.

The mass character of MOOK in itself will become an important factor of introduction of innovations in process of their development.

\section{Social Economic Policy Of Wellbeing Of Digital ERa}

The fissile advocate of the idea that inequality undermines economic body height is the economist, the Nobel Prize laureate Joseph Shtiglits who considers that the middle class is too weak to support consumer expenses at that level which provided economic body height. Apparently, Robert Solow who in 1987 got the Nobel Prize for works about importance of technological innovations from the point of view of long-term economic body height agrees with it. Of an interview in January, 2014 he said in one that "the growing inequality promotes a blurring of structure of distribution of income, and we lose stable jobs for the middle class and the steady income of the middle class which provides a reliable source of the consumer demand keeping development of the industry and stimulating innovations.

The government after all should take some steps for counteraction to the growing threat to welfare of people which is created by development of technologies [11-17].

The guaranteed income on everyone, or, in other words, represents the guaranteed level below which even the one who is not capable to provide himself cannot fall not only absolutely lawful protection against risk to which all are subject, but simply obligatory element of society as whole where the individual counts on support of that small group to which he belongs on the birth". The guaranteed income has nothing in common with equality or equitable distribution. It is the efficient tool of social and economic policy. Basic income not only guarantees an efficient solution of the problem of social wellbeing, but also does not demand the considerable administrative expenses.

The guaranteed income should not weaken an incentive to work for people. It is necessary to pay marginal basic income to all adult citizens at a stage of its tutoring for retraining. We have to fall into to education as to public benefit. It is favorable to all of us that people around us were better formed; as a rule, higher common education level promotes formation of more developed civil society and more efficient economy. In spite of the fact that eventually more and more types of works will carry out robots, neuronets and programs, it is clear to all that in the near future the economy will depend still strongly on human hi-tech work.

Interaction of high technologies with economy has to provide social and economic wellbeing. The natural technology of transition to healthy activity and the economy maintaining health will help society to reach social and economic wellbeing.

The natural technology of transition to healthy activity helps the person to gain, first, improving abilities for achievement of a healthy state, secondly, to develop skills of saving of health for preservation of a healthy state, thirdly, to pass to annual healthy activity in various natural, house and social conditions [11-20].

The economy maintaining health provides economic wellbeing. A basis of economic wellbeing is the uniform [21-27].

\section{ECONOMiC Model OF Global Wellbeing}

Key parameter of financial balance of the population of territories is the starting norm of healthy activity for all participants of economic processes and social programs. The starting norm of healthy 
activity allows to provide economic wellbeing globally. For this purpose the quantity of money in economy of territories has to be always enough for production and consumption of products, goods and services of healthy activity by the population living on it. It is also necessary to provide the uniform regulation of pricing taking into account a demographic situation and the changing demand and offers in the market.

Financial balances of the uniform economy have to provide all participants of economic economic activity and social programs with finance for healthy activity.

Let PC - product cost,

QPG - quantity of production goods,

MCG - market cost of the goods,

$\mathrm{NP}$ - number of participants in products,

NPP - number of producers products,

D - demand,

MP - market profit,

APF - assignments from profit in funds;

$\mathrm{AP}$ - appropriated profit,

SENHL - social and economic norm of healthy life,

LP - labor productivity.

Then

QPG $x(M C G-C \Pi)=M P$;

$\mathrm{AP}=\mathrm{MP}-\mathrm{APF}$

AP/SENHL $=$ NP;

$\mathrm{QPG} / \mathrm{NPP}=\mathrm{LP}$.

At $100 \%$ demand for healthy life D $\geq$ QPG, AP provides all its participants with the finance for healthy life. Deductions from market profit, first, arrive in budgetary fund and are spent under the state order in budgetary sphere. Secondly, arrive in social funds of support of children, parents looking after kids and pensioners.

Strategic priority directions innovative health saving up uniform economy are, first, maintenance of the population with the goods, services and conditions of a life of healthy ability to live, secondly, completion of resources, thirdly, environment ecology.

Maintenance of the population with starting social and economic norm of healthy life is carried out by uniform regulation of pricing from a position of realization of the future demand for healthy ability to live.

Let $\{\mathrm{Xi}\}-$ set of the goods in the market, where $\mathrm{i}=1 \ldots \ldots \ldots \mathrm{n}$;

$\mathrm{Xi}$ - quantity of i goods;

$\mathrm{Ci}$ - cost of resources on manufacture $\mathrm{Xi}$ of the goods;

$\mathrm{Ki}$ - quantity of employees participating in manufacture and realization Xi of the goods;

NHL - norm of healthy ability to live;

$\mathrm{WFi}$ - a wages fund of employees participating in manufacture and realization Xi of the goods; where $\mathrm{WFi} \geq(\mathrm{Ki} \times \mathrm{NHL})$ for all $\mathrm{i}$;

$\mathrm{Pi}$ - profit on realization Xi of the goods in the market, where Pi $>$ WFi for all $\mathrm{i}$;

PGMi - the price of i goods in the market;

$\mathrm{K}$ - quantity of the population; 
$\mathrm{P}$ - cumulative market profit, where $\mathrm{P}=\sum \mathrm{Pi}$;

If PGMi > (WFi $+\mathrm{Ci})$ : Ki for all $\mathrm{i}$; that $\mathrm{P}: \mathrm{K} \geq \mathrm{NHL}$;

If $\mathrm{WFi}<(\mathrm{Ki} \times \mathrm{NHL})$ increases PGMi, that PGMi $>(\mathrm{WFi}+\mathrm{Ci}): \mathrm{Ki}$.

If financial balances of all levels provide a condition 1, then they maintain social and economic stability of society by starting standard of financial wellbeing (Figure 4).

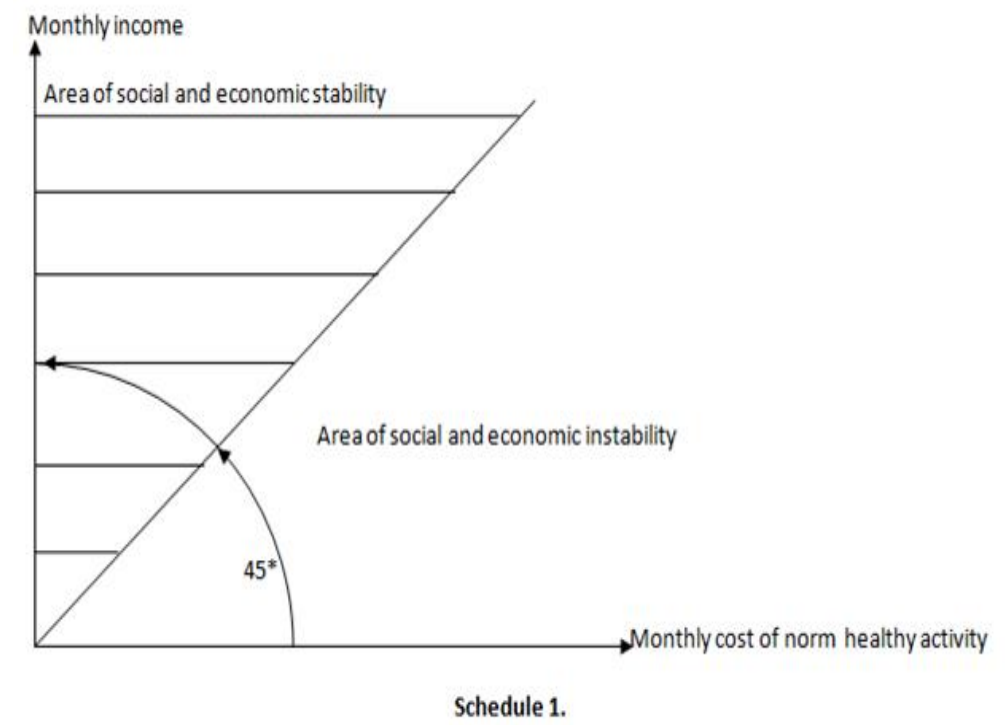

Figure 4

\section{ASPECTS OF REALIZATION ECONOMIC WELlbEING}

For ensuring global economic wellbeing, the government of the countries, the authorities of regions and cities together with departments and the enterprises of various branches of economy count balances of the country, regions, cities and their inhabitants which have to provide financially realization of products, goods and services of healthy activity and their consumption.

The states set the fiscal rule for heads of the enterprises:

- To provide with a salary of each employee of not less monthly cost of products, goods and services of healthy activity.

Regulation mechanisms for deduction of a ratio of the price, the salary, costs of production of products, goods, services and profit within social and economic stability turn on:

1. Market mechanism of regulation by the enterprises increase in labor productivity and quality of production.

2. Market mechanism of regulation by sectors of economy and branches equilibrium prices.

3. It is market - the state interindustry mechanism of regulation of global economic wellbeing adjustment of the equilibrium prices.

4. State mechanism of regulation of system violation of a ratio by 1 enterprises, sectors of economy and branches establishment of the equilibrium prices.

And also fiscal rules of economy work:

A. Lack of speculative operations.

B. The prices decrease if quality has worsened.

C. Taxes are collected for payment of the immaterial optimized work and social programs.

D. Realization of products of goods of services in territories is optimized.

Drawing up financial balance of the population of urban and rural areas requires scoping of financial security of activity of subjects of managing and local governments, coordination of material and 
material and financial and cost proportions at the micro level, definition of sources of formation of financial resources of subjects of managing and local governments, definition of the directions of use of financial resources by subjects of managing and local governments. The financial balance of the population of urban and rural areas represents the set of all income and expenses. He considers professional opportunities of a labor resource, economic and economic opportunities of territories for their development and improvement of quality of life of the population. He helps to pursue effective migration policy in territories of the country.

Correctly made financial balance of the population of urban and rural areas maintains market balance of supply and demand.

Macroeconomic balance is reached as result of joint actions of the state and business, factors of production, supply and demand at which a way of use of production resources for creation of various products, goods and services and their distribution between citizens of the population are balanced. Balance is stable use of all resources and optimum realization of economic interests of all citizens of the population in all sectors, spheres, structural elements of economy.

Dynamic balance is reached by regulation of pricing and inter industry balance the equilibrium prices.

The effective mechanism of stabilization of global economic wellbeing is carried out by purchasing power, solvent demand, an equilibration of the prices, optimum increase in pensions and grants, the balanced budgets of the states, positive balances export import by both internal and external investments on implementation of projects of ensuring global economic wellbeing [4-8]. Investment into ecological projects, projects on health to maintenance and projects on improvement of quality of life.

\section{CONCLUSION}

The whole world in general now is passed through very important economic and social transformations, and the major place in them is taken by technologies. In our changeable world body height of economy and competitiveness are intimately bound to digital economy.

For many people the digital economy becomes the best place for searching of their following work or opportunities for business. Fast change of technologies during an era of digital economy and an artificial intelligence demands formation of hi-tech labor market according to technological achievements of research activity. Business which loses demand for production has to organize retraining of employees on the new production technology in advance and do the order to the universities on preparation of young shots. Business together with the universities have to develop strategy of training for hi-tech labor market. The authorities need to develop strategy of formation of budgets under hi-tech labor market and to exercise project management of modernization of structural updating of sectors of economy at the interindustry level.

Body height of economy and competitiveness completely depends on opportunities in digital economy. The international digital economy uses the Internet as the global platform for communication, trade, expression of people as persons and, of course, for innovations. Open Internet access, with minimum barriers to a data flow and various services from various countries, is a support for success of digital economy. It allows the enterprises and their workers to sell the goods to anyone on all globe, to communicate with clients and also to develop the skills.

Rates of technological development constantly grow, bringing with themselves new opportunities. The digital economy is a basis which allows to create qualitatively new models of business, trade, a logistics, production. It changes a format of education, health care, public administration, communications between people, and, therefore, sets a new paradigm of development of the state, economy and all society. The digital industry allows to develop economic and technological policy, the industry, infrastructure, to form the open, free business environment and flexible labor market, to solve problems which will allow to provide long-term body height.

So far digital revolution captured practically all kinds of activity and involved a majority of mankind in the orbit. Demand for the experts necessary for creation of infrastructure of digital economy increases. Digital revolution supplements and significantly expands possibilities of generation, processing, transfer, accumulation and assimilation of information. The computer forgets nothing, dissemination of information is possible, it is possible to program any as much as necessary 
composite algorithm of routine human activity and to transfer him to execution to robots. Digital revolution finally exempts the person from need of the monotonic and hard work, not only physical, but also room. It releases time which earlier people spent for production of goods and services, and opens a possibility of transition to exclusively creative activity before mankind.

The control system of economy learned it technologically and to reconstruct institutionally, in time to curtail the outdate productions, cutting off the unefficient enterprises from resources and helping leaders to master the latest technologies.

The system of rating of citizens introduced now in the People's Republic of China better than any monitoring stimulates their creative creative activity. The people who positively are proving on production, performed by commercial and social obligations, honestly running business and the respecting ethical standards automatically are highly appreciated and enjoy support in business relations the systems of state regulation and to move ahead on a career ladder. Unfair, immoral, optional and, especially, the corrupted and having criminal bents of the person, on the contrary, leave from all forms of the state support and advance. The similar system is created also for legal entities.

Each country will build the option of digital society, taking into account characteristic traditions and ethical standards. In the long term the share of the people with creative motivation who are guided in the behavior by scientific knowledge, logical thinking, rational reasons has to increase. In this sense the mankind waits for quantum economic leap due to the multiple increase in creative activity of people.

Development of digital technologies can promote transition to the nature to figurative nanotechnologies. The digital systems of processing of larger data by mathematical methods can help researchers to reveal fundamental regularities of formation of nano structures on larger selections of a set of the experimental datas of creation of nano substances in vitro. In turn, these fundamental regularities will rouse to creation of nanotechnologies on the basis of processes of the nature. Such technologies will lead to the continuous use of resources and the received substances and materials preserving the nature in production. The nature figurative nanotechnologies do not break ecology and harmony of a surrounding medium.

It is necessary to create on the basis of the open international technological platform the wide coalition of the countries interested in development of digital systems for creation the nature of the figurative nanotechnologies so relevant for preservation of ecology, and as a result for preservation of life on the earth.

\section{REFERENCES}

[1] Ford M. Technologies which will change the world. - M.: Mann, Ivanov and Ferber, 2014.

[2] Evgeniy Bryndin. Cognitive Robots with Imitative Thinking for Digital Libraries, Banks, Universities and Smart Factories. International Journal of Management and Fuzzy Systems. V. 3, N. 5, 2017, pp 57- 66.

[3] Evgeniy Bryndin. Program Hierarchical Realization of Adaptation Behavior of the Cognitive Mobile Robot with Imitative Thinking. International Journal of Engineering Management. Volume 1, Issue 4. 2017, pp. 74-79.

[4] Bryndin E.G. Cognitive robots with imitative thinking and adaptive behavior. International forum "Intellectual Systems of the 4th Production Revolution" - II International. conf. "Cognitive robotics". TGU. 2017.

[5] Evgeniy Bryndin. Technological Thinking, Communication and Behavior of Androids. Communications. Volume 6, Issue 1. 2018. Pages: 13-19

[6] Evgeniy Bryndin. Construction and Continuous Processing of Programs with Determinate-Connected Modules. International academic journal "Electrical and Computer Engineering", Volume 1, Issue 1. 2017, pp. 1-8.

[7] Bryndin E.G. Optimum organization and management of processing of programs. X Inter. conf. "Management of development of large-scale systems (MLSD’2017". T. 2. 2017. Page 428-430.

[8] Bryndin E.G. Management of collective competence of innovative activity. International scientific practical conf. "The modern trends of the Russian economy". T.2. 2017. Page 289-292.

[9] E.G. Bryndin Cross-disciplinary technological culture of a becoming of scientific and educational society. International conf. "Human measurement of the university". TGU publishing house. 2017. Page 11-15.

[10] Bryndin E.G. Innovative development with a support on hi-tech education. Inter. conf. "Problems of sustainable development of Russian regions". TIU. 2017. Page 286-291 
[11] E. G. Bryndin, I. E. Bryndina. Sanatorium Rehabilitation of the Population by the Healthy Lifestyle. International journal "Rehabilitation Sciences", Volume 2, Issue 2. USA. 2017. P. 35-40.

[12] 77. Bryndin E.G., Bryndina I.E. Normalization of Psyche by Healthy Lifestyle of Various Groups of the Population. American Journal of Applied Psychology. V. 6, № 4. 2017, Pages: 51-56.

[13] E. G. Bryndin, I. E. Bryndina. Formation of Public Health Care on Basis of Healthy Lifestyle. International Journal of Psychological and Brain Sciences. Vol. 2, No. 3, 2017, pp. 63-68.

[14] Bryndin E.G., Bryndina I.E. Natural Measures of Normalization of Vital Systems of the Person for Maintaining of the Healthy State. International Physical Medicine \& Rehabilitation Journal. V.3 Issue 1. 2018. 8 pages. URL: http://medcraveonline.com/IPMRJ/IPMRJ-03-00069.php

[15] E.G. Bryndin. Stages of transition to a healthy lifestyle. Inter. Congress "The healthy World - the healthy Person". Alushta. 2013. Page 45-49

[16] Bryndin E. G., Bryndina I.E. Health care on the basis of a healthy lifestyle. Scientific journal "National Health", N. 1. 2017. Page 34-42.

[17] E.G. Bryndin, I.E. Bryndina Management of social infrastructure of formation of the healthy lifestyle of the population. Conf. "Social formation of the XXI century: history, the present, prospects of a profession "Social work" in Russia. 2014. Page 171-174.

[18] Bryndin E. G., Bryndina I. E. Cultural and infrastructure aspects of public health care. Scientific journal "National Health", N. 1. 2017. Page 51-62.

[19] Bryndin E.G., Bryndina I.E. Normalization of Cognitive Thinking by Healthy Lifestyle. ARC Journal of Public Health and Community Medicine. V. 1, Issue 2, 2016, PP 1-6.

[20] Bryndin E.G., Bryndina I.E. Healthy Wellbeing of the Person and Society. Journal "The European Proceedings of Social \& Behavioural Sciences EpSBS”. V. XIX. 2017. Pages 130-139.

[21] Bryndin E.G. Becoming of global wellbeing. V Inter. Scientific congress "GLOBALISTIKA-2017": GLOBAL ECOLOGY AND SUSTAINABLE DEVELOPMENT. 2017. URL: https://lomonosovmsu.ru/archive/Globalistics_2017/data/10145/uid135884_report.pdf

[22] Evgeny Bryndin. Economic Aspect of Global Wellbeing. Journal "The European Proceedings of Social \& Behavioural Sciences". Volume VII. 2016. Pages 14-21

[23] Bryndin E.G. Development of biotic spaces. X International Kondratyevskaya conf. "SCIENTIFIC HERITAGE of N.D. Kondratyev AND PRESENT". Moscow: Publishing house: Interregional public organization of assistance to studying, promotion of scientific heritage of N.D. Kondratyev. 2017. Page 76-82.

[24] Bryndin E.G. Development of the digital sector of economy. V International sociological forum: "Dynamics of social transformation of the Russian society: regional aspects". TumSU. 2017. Page 982-986

[25] Bryndin E.G. Optimum control of innovative agricultural economy. VI International scientific and practical conference "Theoretical and Applied Researches of Social and Economic Systems in the conditions of Integration of Russia into World Economy". TumSU. 2017. Page 357-361.

[26] Bryndin E.G. Creative management of diversification of economy. V international sociological forum: "Dynamics of social transformation of the Russian society: regional aspects". TumSU. 2017. Page 977-981

[27] E.G. Bryndin. Harmonization of a civilization by spiritual perfecting. Germany: LAP LAMBERT Academic Publishing. 2018. 132 pages.

\section{AUTHOR'S BIOGRAPHY}

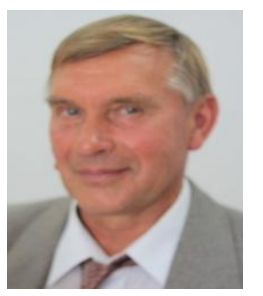

Evgeniy G. Bryndin, Director of Research Center "NATURE INFORMATIC", Novosibirsk. Technological platform FUTURE MEDICINE, Russia. National Supercomputer Technological platform, Russia. Member of the International American Academy of Education. Leader of social movement "MORAL RUSSIA". The ambassador of the world of the International federation UPF

Citation: Evgeniy Bryndin. "Technological, Economic and Social Aspects of Management by Development of the Digital Industry 4.0" International Journal of Managerial Studies and Research (IJMSR), vol 6, no. 4, 2018, pp. 19-30. doi:http://dx.doi.org/10.20431/2349-0349.0604003.

Copyright: () 2018Authors. This is an open-access article distributed under the terms of the Creative Commons Attribution License, which permits unrestricted use, distribution, and reproduction in any medium, provided the original author and source are credited. 